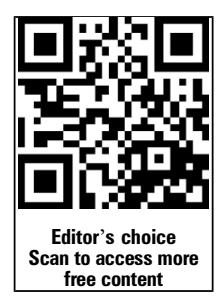

free content

\title{
Carotid artery stenting in nonagenarians: are there benefits in surgically treating this high risk population?
}

\author{
Michael M Wach, 1,2 Travis M Dumont, 1,2 Hakeem J Shakir, 1,2 \\ Kenneth V Snyder, ${ }^{1,2,3,4,5}$ L Nelson Hopkins, ${ }^{1,2,4,5,6}$ Elad I Levy, 1,2,4,5 \\ Adnan H Siddiqui ${ }^{1,2,4,5,6}$
}

${ }^{1}$ Department of Neurosurgery, University at Buffalo, State University of New York, Buffalo, New York, USA ${ }^{2}$ Department of Neurosurgery, Gates Vascular Institute, Kaleida Health, Buffalo, New York, USA ${ }^{3}$ Department of Neurology, University at Buffalo, State University of New York, Buffalo, New York, USA ${ }^{4}$ Department of Radiology, University at Buffalo, State University of New York, Buffalo, New York, USA

${ }^{5}$ Toshiba Stroke and Vascular Research Center, University at Buffalo, State University of New York, Buffalo,

New York, USA

${ }^{6}$ Jacobs Institute, Buffalo,

New York, USA

\section{Correspondence to}

Dr A H Siddiqui, Department of Neurosurgery, University at Buffalo, 100 High Street, Suite B4, Buffalo, NY 14203, USA; asiddiqui@ubns.com

Received 25 November 2013 Revised 20 January 2014 Accepted 21 January 2014 Published Online First 6 February 2014

\section{ABSTRACT}

Background Carotid angioplasty and stenting (CAS) is considered desirable treatment for patients at high risk for carotid endarterectomy. Despite a growing elderly population, scant data exist on CAS in nonagenarians. Nonagenarians represent a high risk population for open and endovascular interventions due to unique anatomic and physiologic characteristics presenting significant challenges to anesthesiologists and surgeons. Studies have quantified that symptomatic and asymptomatic patients should survive 2 and 5 years, respectively, to gain benefit from revascularization; thus doubt exists on the value of CAS in nonagenarian patients because of their extreme age and unique risk factors. We therefore evaluated CAS safety and efficacy in our hospital's nonagenarian population.

Methods CAS cases performed in patients aged $\geq 90$ years between April 2005 and January 2013 were retrospectively examined. Relevant demographic and medical data were reviewed. Rates of perioperative complications and complications until end of follow-up (including stroke, myocardial infarction, death) were compiled.

Results Among 21 nonagenarian cases of stent placement performed in 20 patients (11 symptomatic, nine asymptomatic), two patients suffered perioperative stroke after undergoing CAS and one died during the perioperative period. $50 \%$ of symptomatic patients were alive at 19 months; $50 \%$ of asymptomatic patients were alive at 47 months.

Conclusions CAS in nonagenarian patients carried increased risk of perioperative ischemic events, compared with contemporary trial results in symptomatic and asymptomatic patients. Further, mean survival time postprocedure fell short of guidelines for receiving procedural benefit. Although larger scale multicenter research is needed, we recommend careful consideration of overall health status when contemplating stenting in nonagenarians.

\section{INTRODUCTION}

CrossMark

To cite: Wach MM, Dumont TM, Shakir HJ, et al. I Neurolntervent Surg 2015;7:182-187.
Carotid artery stenting (CAS) is a valued method of treatment for cases of carotid stenosis in symptomcarotid endarterectomy (CEA). Although CAS has many benefits in the treatment of carotid stenosis, advancing age has been an area of concern for the risk of perioperative complications. ${ }^{1-4}$ The role of atic and asymptomatic patients at high risk for carotid revascularization in nonagenarians in particular is unclear given that the risk-benefit ratio for this particular population remains understudied. With the general population now living to advanced ages, ${ }^{5}$ understanding the role of CAS in those patients 90 years and older is a relevant topic.

Following an initial symptomatic ischemic episode, elderly patients are almost $60 \%$ more likely to have recurrent stroke than younger patients $(3.8 \%$ vs $2.4 \%)$, making surgical intervention desirable. ${ }^{6}$ However, CAS in elderly populations has been subsequently shown to carry an increased risk compared with CEA, most notably in the large scale Carotid Revascularization Endarterectomy versus Stenting Trial (CREST). ${ }^{7}$ Moreover, carotid revascularization in asymptomatic cases of carotid stenosis is especially under question in elderly patients due to concerns that benefits may be negligible compared with the risk of the procedure. With advancement of technology and techniques, more recent work has begun to support CAS as a possibly desirable approach in both symptomatic and asymptomatic patients who are 80 years and older. ${ }^{6} 8$ This work also includes the 3 year results of the Stenting and Angioplasty with Protection in Patients at High Risk for Endarterectomy (SAPPHIRE) trial, which showed no difference in outcomes between CEA and CAS treatment groups in higher surgical risk patients. ${ }^{9}$ Nevertheless, a paucity of research has been reported concerning the application of CAS specifically in those patients 90 years of age or older ${ }^{10} 11$ and, rightfully, concerns remain.

It is likely that age related anatomic and physiologic considerations make revascularization with CAS more difficult and perioperative complications more frequent in elderly patients. ${ }^{12-14}$ Complex anatomy of the aging aortic arch and great vessels, such as a type III or a bovine arch, and acute angles and tortuosity from elongation of the carotid arteries, make performance of the CAS procedure technically difficult. ${ }^{12-16}$ These anatomical abnormalities are found more commonly in elderly patients and tend to be associated with a higher rate of periprocedural complications. $^{3616}$ Besides the procedural risk that CAS carries in this population, the expected longevity of nonagenarians is less than that of younger patients, such that the long term benefits of carotid revascularization may be neutralized. Frequently quoted studies 
suggest that survival in excess of 2 and 5 years is required for any benefit from revascularization for symptomatic and asymptomatic patients, respectively. ${ }^{17} 18$ Thus, due to the extreme age of this patient population, questions arise about meaningful longevity after revascularization. All of this has led to growing concerns in the existing literature about treatment of stroke and asymptomatic carotid stenosis in nonagenarians. ${ }^{19} 20$

As the best treatment strategy remains unclear, our investigators have favored CAS in this patient population when the patient's baseline health status is good (modified Rankin Scale score of 0 , with no or few comorbidities, and no recent transient ischemic attack (TIA) or minor stroke for asymptomatic patients) or due to patient preference. Consequently, we were able to obtain data on nonagenarians undergoing CAS, a patient group of less common presentation. The purpose of this study was to review a single center experience of carotid stenting in nonagenarians, with the primary outcomes of interest including major adverse perioperative events and stroke free survival postprocedure.

\section{METHODS}

A prospectively maintained database of elective neuroendovascular procedures at our hospital was searched for consecutive cases of extracranial internal CAS procedures performed for symptomatic or asymptomatic atherosclerotic stenosis between April 2005 and January 2013. At our hospital, CAS is performed for patients with high risk anatomic or physiologic criteria for CEA, as delineated in previous trials, ${ }^{17}{ }^{21}$ with stenosis in excess of $50 \%$ for symptomatic and $80 \%$ for asymptomatic patients, measured by the North American Symptomatic Carotid Endarterectomy Trial (NASCET) criteria $^{21}$ or due to patient preference. Possible preoperative risk factors (although not defined as absolute contraindications) to CEA included, but were not fully limited to, age older than 80 years, congestive heart failure, peripheral vascular disease, chronic obstructive pulmonary disease, renal failure, contralateral carotid artery occlusion, recurrent ipsilateral carotid artery stenosis, ipsilateral hemispheric symptoms within 6 weeks, stenosis of the ipsilateral internal carotid siphon, and stenosis of the ipsilateral external carotid artery. ${ }^{17} 2122$ Only patients who were 90 years or older at the time of the procedure were included in this study, and cases of dissection and total occlusion were excluded. Relevant demographic and medical data were reviewed, including age, gender, presence of vascular disease, vascular disease risk factors (eg, cigarette smoking, hypertension, hyperlipidemia, and diabetes mellitus), as well as comorbid conditions (eg, coronary artery disease, peripheral vascular disease, and previous TIA or stroke not related to the current presentation). Case details were also reviewed, including nature of symptoms, if present (eg, TIA or ischemic stroke); pre-existent neurological compromise (measured by the National Institutes of Health Stroke Scale); degree of stenosis (measured according to NASCET criteria ${ }^{21}$ ); and anatomic factors, including aortic arch type and high risk lesion features (plaque ulceration or pseudo-occlusion). Procedural details were noted, including anatomic detail of aortic arch configuration, plaque ulceration, degree of stenosis, and the occurrence of intraprocedural or periprocedural (within the first 30 days after the procedure) neurological complications, including stroke (new cerebral ischemia or hemorrhage with decline in neurological examination), myocardial infarction (MI), ${ }^{23}$ or death. In patients for whom follow-up data were available, the incidences of stroke, MI, and death were observed until the end of our follow-up period (up to 5 years postprocedure or death).
Public obituary records were used to assess for mortality in all patients.

The primary outcome of interest was the combined incidence of major perioperative complications (stroke, MI, or death), as well as all complications until the end of the follow-up period. Continuous data are reported as mean \pm SD and compared with analysis of variance. Binomial data are reported as a percentage and were assessed using the two tailed Fisher's exact test. For analysis, variables with $\mathrm{p}$ values $<0.05$ were deemed significant. Censored data Kaplan-Meier survival curves were created for symptomatic and asymptomatic patients. The symptomatic Kaplan-Meier survival curve was qualitatively compared with theoretical 'best case' (90-year-old woman with TIA, anticipated survival 4.69 years) and 'worst case' (99-year-old man after ischemic stroke, anticipated survival 2.19 years) anticipated survival extrapolated from population data ${ }^{24}$ and actuarial life expectancy data from 2009 published by the USA Social Security Administration. ${ }^{25}$ The asymptomatic Kaplan-Meier curve was qualitatively compared with 'best case' (defined above) and 'worst case' (defined above) anticipated survival extrapolated from the same sources. Censored survival data were reported as median in years. Statistical analysis was performed with GraphPad Prism (V.6.0; GraphPad Software Inc, La Jolla, California, USA).

The local institutional review board approved the collection of data for the completion of this retrospective study.

\section{RESULTS}

A total of 20 patients (average age 92.4 years, 14 men) with 21 treated lesions were identified who were 90 years of age or older at the time of CAS. This included 11 symptomatic patients (presenting with ischemic stroke or TIA) and nine asymptomatic patients with 10 asymptomatic lesions. Demographic and relevant health data were compiled for all patients and are displayed in table 1. Complex aortic arch anatomy was present in nearly all patients, including type II arch in five cases and type III arch in 10 cases (nine patients) (tables 2, 3).

In the symptomatic subgroup, two perioperative complications occurred (one stroke and one death) in 11 procedures (18.2\%). There were no findings of MI or intracranial hemorrhage that occurred within 30 days. There was one additional stroke that occurred after 30 days (symptomatic case No 2: stroke at 16 months postoperatively (death at 19 months)). Among the 11 patients, median follow-up was 17 months (range 0-67 months with combined 19.6 person years of follow-up), with 50\% survival for symptomatic patients in our cohort at 19 months. Of the 11 patients, six patients had died. The median stroke free survival was 17 months (range 0-67 months). One case with 0 months of event free follow-up was a perioperative infarct (symptomatic case No 6). This patient remains otherwise event free 52 months postoperatively. Case by case results are summarized in table 2 .

In the asymptomatic subgroup, one perioperative complication (ischemic stroke) occurred among the 10 procedures $(10.0 \%)$. There were no perioperative cases of MI, intracranial hemorrhage, or death. One patient was lost to follow-up after the initial hospitalization and was not included in the stroke free survival analysis; review of public obituary records showed no match for this patient. Among the eight patients with follow-up data available, median follow-up was 15 months (range 5-93 months, with combined 19.1 person years of follow-up), with $50 \%$ of asymptomatic patients alive at 47 months. Among the nine patients, two had died. The median stroke-free survival was 47 months. Case by case results are summarized in table 3 . 
Table 1 Demographics and clinical characteristics

\begin{tabular}{|c|c|c|}
\hline Characteristic & Symptomatic & Asymptomatic \\
\hline No of cases & 11 & 10 \\
\hline Average age (years) & 91.9 & 93 \\
\hline Male gender ( $(\%))$ & $7(63.6)$ & $7(70.0)$ \\
\hline \multicolumn{3}{|l|}{ Ethnicity (n (\%)) } \\
\hline Caucasian & $11(100.0)$ & $10(100.0)$ \\
\hline African-American & $0(0.0)$ & $0(0.0)$ \\
\hline Other & $0(0.0)$ & $0(0.0)$ \\
\hline Hypercholesterolemia (n (\%)) & $7(63.6)$ & $6(60.0)$ \\
\hline Hypertension (n (\%)) & $9(81.8)$ & $6(60.0)$ \\
\hline Diabetes mellitus ( $\mathrm{n}(\%)$ ) & $2(18.2)$ & $5(50.0)$ \\
\hline \multicolumn{3}{|l|}{ Cigarette smoking (n (\%)) } \\
\hline Never & $6(54.5)$ & $5(50.0)$ \\
\hline Former & $5(45.5)$ & $5(50.0)$ \\
\hline Active at presentation & $0(0.0)$ & $0(0.0)$ \\
\hline Premorbid CAD* (n (\%)) & $5(45.5)$ & $6(60.0)$ \\
\hline Previous ischemic stroke or TIA† (n (\%)) & $3(27.3)$ & $3(30.0)$ \\
\hline Average preoperative NIHSS score & 4.20 & 0.00 \\
\hline TIA as presentation ( $\mathrm{n}(\%))$ & $5(45.5)$ & $0(0.0)$ \\
\hline Plaque ulceration (n (\%)) & $2(18.2)$ & $0(0.0)$ \\
\hline $\begin{array}{l}\text { Average degree of stenosis ( } \% \text { of vessel } \\
\text { lumen) }\end{array}$ & 70.9 & 84.2 \\
\hline \multicolumn{3}{|c|}{$\begin{array}{l}\text { *Premorbid coronary artery disease is defined as a known diagnosis prior to a stroke } \\
\text { event. } \\
\text { PPrevious ischemic stroke/TIA indicates a past history of ischemic events before the } \\
\text { intervention in this study was performed. } \\
\text { CAD, coronary artery disease; NIHSS, National Institutes of Health Stroke Scale; TIA, } \\
\text { transient ischemic attack. }\end{array}$} \\
\hline
\end{tabular}

\section{DISCUSSION}

In the present study of CAS in nonagenarians, the perioperative complication risk was $18 \%$ in symptomatic patients and $10 \%$ in asymptomatic patients. These were particularly elevated rates of complications compared with rates from a sample of our overall
CAS population, ${ }^{26} 27$ which also included some of the patients in this study. Not unexpectedly, in our institution's general CAS population (average age 71.4 years), combined perioperative events (stroke, hemorrhage, MI, death) occurred at a lesser rate in both symptomatic and asymptomatic patients than in nonagenarian patients. ${ }^{26} 27$ These data, in concurrence with data from other studies, ${ }^{1-3} 728$ suggest that symptomatic and asymptomatic patients of advanced age who undergo stenting are at a higher risk of perioperative complication and must be examined further.

An observation of this case series was the increase in perioperative ischemic complications among endovascularly treated patients with difficult aortic arch anatomy. Unfortunately, but not surprisingly, unfavorable aortic arch configuration is common in the nonagenarian population (present in $75 \%$ of cases in this series). Previous work has suggested that unfavorable aortic arch anatomy is correlated with higher complication risk with carotid stenting ${ }^{12} 1416$ and, as such, we theorize that complications should be expected to be greater than average in nonagenarian patients due to the higher prevalence of unfavorable arch anatomy. This may represent a potential prognostic factor in selecting patients for surgical intervention and could also be of importance in the future when considering patients for direct cervical carotid access techniques. ${ }^{29}$

Additionally, on further examination of our case series, an intentional source of bias was found. Although patients were chosen for CAS at our institution because they exhibited some amount of known physiologic and anatomic risk factors to CEA (most obviously age $>80$ years), there was also intentional bias towards patients with good prognostic factors who were perceived to have favorable longevity when original selection was made for CAS in patients of such old age. In particular, although patients 90 years and older have many risk factors, patients offered CAS at our institution in this dataset tended to have few or no comorbidities or have comorbidities that were well controlled, had a 0 score on the modified Rankin Scale,

Table 2 Symptomatic nonagenarians

\begin{tabular}{|c|c|c|c|c|c|}
\hline $\begin{array}{l}\text { Patient } \\
\text { No }\end{array}$ & Medical history & $\begin{array}{l}\text { Anatomical } \\
\text { considerations }\end{array}$ & $\begin{array}{l}\text { Type of embolic } \\
\text { protection }\end{array}$ & $\begin{array}{l}\text { Type of } \\
\text { stent }\end{array}$ & $\begin{array}{l}\text { Complications and/or last clinical } \\
\text { follow-up }\end{array}$ \\
\hline 1 & Hyperlipidemia, CAD, CKD & Type III arch, calcified arch & EPI filter wire, distal & Wallstent & Death at 4 months \\
\hline 2 & Hyperlipidemia, HTN, CAD & Type II arch, bovine arch & Accunet 5,5 & Acculink & Stroke at 16 months, death at 19 months \\
\hline 3 & $\begin{array}{l}\text { Hyperlipidemia, HTN, CAD, AFIB, former } \\
\text { smoker }\end{array}$ & Tortuous innominate & EPI filter wire, distal & Xact & Death at 9 months \\
\hline 4 & $\begin{array}{l}\text { Hyperlipidemia, HTN, CAD, previous stroke/ } \\
\text { TIA, former smoker }\end{array}$ & $\begin{array}{l}\text { Type III arch, tortuous } \\
\text { innominate }\end{array}$ & EPI filter wire, distal & Xact & Death at 23 months \\
\hline 5 & Hyperlipidemia, HTN, previous stroke/TIA & Type III arch, bovine arch & EPI filter wire, distal & Xact & Event free 67 months follow-up \\
\hline 6 & Previous stroke/TIA & $\begin{array}{l}\text { Type III arch, tortuous } \\
\text { innominate }\end{array}$ & EPI filter wire, distal & Xact & $\begin{array}{l}\text { Stroke within } 30 \text { days, no other events, } \\
52 \text { months follow-up }\end{array}$ \\
\hline 7 & HTN & None & EPI filter wire, distal & Xact & Death at 21 months \\
\hline 8 & HTN, DM 2, CAD, former smoker & $\begin{array}{l}\text { Type II arch, tortuous } \\
\text { innominate }\end{array}$ & EZ filter, distal & Wallstent & Death within 30 days \\
\hline 9 & $\begin{array}{l}\text { HTN, previous stroke/TIA, former smoker, } \\
\text { CKD }\end{array}$ & None & EZ filter, distal & Wallstent & Event free 17 months follow-up \\
\hline 10 & Hyperlipidemia, HTN, DM 2, AFIB & Type II arch & Mo.Ma, proximal & Wallstent & Event free 12 months follow-up \\
\hline 11 & Hyperlipidemia, HTN, former smoker & Type III arch & Mo.Ma, proximal & Wallstent & Event free 10 months follow-up \\
\hline
\end{tabular}

Cases are listed in chronological order of the date on which the procedure was performed.

Column 6 is the time measured from the day of procedure postoperatively to the last follow-up or to an event. There were no complications unless otherwise stated

Previous ischemic stroke/TIA indicates a past history of ischemic events before the intervention in this study was performed.

Manufacturers: Accunet, Abbott Vascular, Redwood City, California, USA; EPI filter, Boston Scientific, Natick, Massachusetts, USA; EZ filter, Boston Scientific; Mo.Ma, Invatec, Roncadelle

Brescia, Italy; Wallstent, Boston Scientific; Xact, Abbott Vascular.

AFIB, atrial fibrillation; CAD, coronary artery disease; CKD, chronic kidney disease; DM 2, diabetes mellitus type 2; HTN, hypertension; TIA, transient ischemic attack. 
Table 3 Asymptomatic nonagenarians

\begin{tabular}{|c|c|c|c|c|c|}
\hline $\begin{array}{l}\text { Patient } \\
\text { No }\end{array}$ & Medical history & $\begin{array}{l}\text { Anatomical } \\
\text { considerations }\end{array}$ & $\begin{array}{l}\text { Type of embolic } \\
\text { protection }\end{array}$ & $\begin{array}{l}\text { Type of } \\
\text { stent }\end{array}$ & $\begin{array}{l}\text { Complications and/or last } \\
\text { clinical follow-up }\end{array}$ \\
\hline 1 & Hyperlipidemia, former smoker & None & $\begin{array}{l}\text { Accunet filter wire, } \\
\text { distal }\end{array}$ & Xact & 93 months follow-up \\
\hline 2 & Hyperlipidemia, former smoker & $\begin{array}{l}\text { Type II arch, tortuous } \\
\text { innominate }\end{array}$ & EPI filter wire, distal & Wallstent & $\begin{array}{l}\text { Stroke within } 30 \text { days, } 93 \text { months } \\
\text { follow-up }\end{array}$ \\
\hline 3 & Hyperlipidemia, HTN, CAD & None & Emboshield, distal & Xact & Death at 47 months \\
\hline 4 & HTN, DM 2, previous stroke/TIA & Type III arch & Angioguard, distal & Precise & $\begin{array}{l}\text { TIA at } 7 \text { months, death at } \\
15 \text { months }\end{array}$ \\
\hline 5 & $\begin{array}{l}\text { Hyperlipidemia, HTN, DM 2, CAD, previous } \\
\text { stroke/TIA, former smoker }\end{array}$ & Type III arch & EZ filter, distal & Wallstent & 34 months follow-up \\
\hline 6 & Hyperlipidemia, HTN, DM 2, CAD & Type II arch & NAV-6, distal & Xact & 15 months follow-up \\
\hline 7 (right) & DM 2, CAD, former smoker & Type III arch & NAV-6, distal & Wallstent & 14 months follow-up \\
\hline 7 (left) & DM 2, CAD, former smoker & Type III arch & EZ filter, distal & Wallstent & 14 months follow-up \\
\hline 8 & Hyperlipidemia, HTN, CAD, AFIB & None & Angioguard, distal & Precise & 5 months follow-up \\
\hline 9 & HTN, previous stroke/TIA & Type III arch & Angioguard, distal & Precise & 5 months follow-up \\
\hline
\end{tabular}

Cases are listed in chronological order of the date on which the procedure was performed.

Column 6 is the time measured from the day of procedure postoperatively to the last follow-up or to an event. There were no complications unless otherwise stated.

Previous ischemic stroke/TIA indicates a past history of ischemic events before the intervention in this study was performed.

Manufacturers: Accunet, Abbott Vascular, Redwood City, California, USA; Angioguard, Cordis, Warren, New Jersey, USA; Emboshield, Abbott Vascular; EPI, Boston Scientific, Natick,

Massachusetts, USA; EZ, Boston Scientific; NAV-6, Abbott Vascular; Precise, Cordis; Xact, Abbott Vascular; Wallstent, Boston Scientific; Xact, Abbott Vascular.

$A F I B$, atrial fibrillation; CAD, coronary artery disease; DM 2, diabetes mellitus type 2; HTN, hypertension; TIA, transient ischemic attack.

and exhibited proper/compliant medication usage. Many of these same factors were also found in recent studies to be of benefit when selecting asymptomatic patients for CEA, with better prognosis. ${ }^{30}$ It must be noted that this bias of selection may have masked an even more serious decrease in mean survival post-CAS in our nonagenarian population compared with our general CAS population, and this may be a point to deliberate in future studies.

Even in the presence of intentional selection, certain risk factors may have played a role in patient survival. Pre-existing coronary risk factors (coronary artery disease and/or hypertension) seemed to influence outcomes-all six symptomatic patients who died had one or both of these factors, as did both asymptomatic patients who died. Although many nonagenarians have active disease processes such as these at presentation, this may be a prognostic factor to examine in future studies.

As stated previously, there was a high rate of perioperative complications (18\%) among the symptomatic patients in the present study. This perioperative complication incidence does not compare favorably with contemporary trial data (from the CREST, which found a rate of $5.2 \%,{ }^{7}$ or from SAPPHIRE, which found a rate of $4.4 \%{ }^{31}$ ). Furthermore, data from studies that specifically observed octogenarians showed perioperative complication rates ranging from $3.3 \%$ to $9.2 \%,{ }^{2} 48$ showing that our nonagenarian data do not compare favorably for this end point, even when compared with other elderly patients. Because increasing age is a known risk predictor for adverse outcomes in CAS, ${ }^{3}$ it is not unexpected that 90 -year-old patients would have worse outcomes than 80 -year-old patients, but it is nonetheless worrisome.

Also, in symptomatic patients in our study, the 50\% survival rate was found to be 19 months. Anticipated survival did not meet the 2 year threshold of benefit from surgical intervention conventionally reported for symptomatic carotid disease based on the NASCET $^{21}$ or compare favorably with extrapolated population based data. For the sake of comparison with the slightly younger population, octogenarians receiving CAS in one study were found to have $85 \%$ survival at 24 months, ${ }^{8}$ easily surpassing the $50 \%$ survival mark of 19 months in our study.
These findings, along with the increased incidence of perioperative complications, led us to question the value of CAS in patients $>90$ years old who present with symptoms of TIA or stroke. This is despite the previously described intentional selection bias toward patients with fewer comorbid conditions who were perceived to have favorable longevity.

In the asymptomatic group, CAS also appeared to be of minimal benefit. A higher than anticipated complication incidence of $10 \%$ is worrisome, although in this small cohort this represents a single complication. Of greater note, the 50\% survival rate found in this study was 47 months, indicating that CAS in these asymptomatic patients did not confer much benefit compared with anticipated survival based on population data. However, developing strong recommendations based on this very small cohort (10 lesions in nine patients) with limited follow-up data (19.1 combined person years among nine patients with follow-up) would be premature. Of note, among nine patients with available follow-up, six remain well, although the follow-up duration is quite limited in four of these patients (5-15 months). As with symptomatic patients, CAS was offered to asymptomatic patients with intentional selection bias towards patients with good baseline health and perceived favorable longevity.

One of the main issues to consider in the nonagenarian population then is weighing the increased risk of perioperative complication and ischemic events during follow up versus the benefit in stroke free survival that patients are to gain from endovascular intervention. As stated previously, frequently quoted studies suggest that survival in excess of 2 and 5 years ( 24 and 60 months) is requisite for symptomatic and asymptomatic patients, respectively, to derive benefit from revascularization. ${ }^{17}{ }^{18}$ In our dataset, $50 \%$ survival rates were 19 months for symptomatic patients and 47 months for asymptomatic patients. Thus, in our series, median survival suggests that CAS was not merited in symptomatic or asymptomatic patients. By using data from Boysen et $a l^{24}$ as well as referencing the social security database $\mathrm{e}^{25}$ and public records, expected stroke free survival curves for cases of carotid stenosis in patients were generated and were compared with the data presented in our study (figures 1,2). Neither survival curve displayed 
Stroke-Free Survival after CAS: Symptomatic Carotid Stenosis

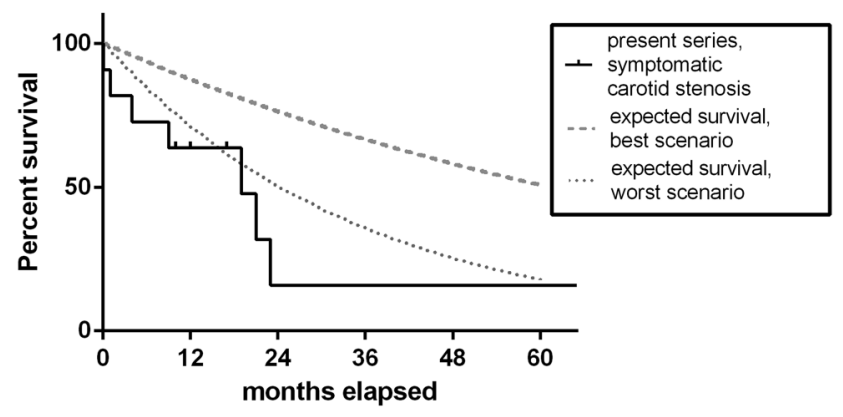

Figure 1 Stroke free survival after carotid artery stenting in symptomatic carotid artery stenosis, as expected for the present series, compared with extrapolated population based data. Survival of symptomatic patients in our cohort fell below even what was the predicted theoretical worst case scenario of a post stroke patient undergoing medical management. Hash marks represent censored data points.

an appreciable improvement against expected survival. Even in nonagenarians who do not experience stroke, there is significant concern of longevity and inhospital mortality, ${ }^{32}$ simply meaning that these patients may be too old to derive benefit and thus casting further doubt as to whether surgical intervention is appropriate for these cases.

Finally, a major consideration in treatment plans for nonagenarians is that other options may be more desirable than CAS. Medical management may be a viable option, especially for asymptomatic cases and low grade stenoses simply because it avoids the complication risks of surgery, a very important factor to consider in an elderly population that is more likely to suffer from such complications. The Stenting versus Aggressive Medical Management for Preventing Recurrent Stroke in Intracranial Stenosis (SAMMPRIS) trial showed that aggressive medical management (aspirin, clopidogrel, and risk factor reduction) was superior to stenting in cases of symptomatic intracranial stenosis, ${ }^{33}$ and the Clopidogrel and Aspirin for Reduction of Emboli in Symptomatic Carotid Stenosis (CARESS) trial even showed promising results in reducing microembolization for carotid stenosis. ${ }^{34}$ However, long term research directly comparing medical management and surgical intervention for symptomatic carotid stenosis remains understudied and even more so in patients over 90 years. Although

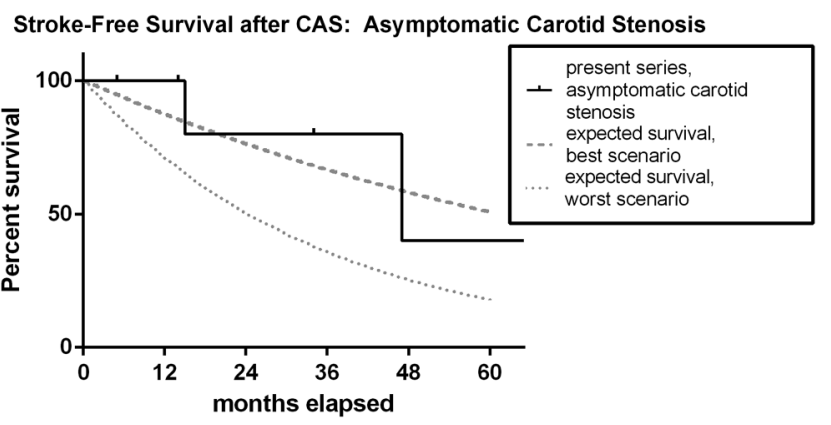

Figure 2 Stroke free survival after carotid artery stenting in asymptomatic carotid artery stenosis, as expected for the present series, compared with extrapolated population based data. Initial survival of the patients in our cohort seemed to do as well or better than the theoretical best case scenario, as predicted with medical management. As time passed, predicted survival fell between the theoretical best and worst case scenarios. Hash marks represent censored data points. the results of SAMMPRIS and CARESS may indicate an expanded role for medical management in the future, there are few data concerning this application in nonagenarians presently and, as such, recommendations cannot be made to its application. Conversely, several studies have shown that CEA can be a viable option in nonagenarians, ${ }^{35-37}$ often times with significantly lesser rates of perioperative complications than CAS. Although CEA expectedly carries a higher risk in nonagenarians than in younger population, it still seems to represent an adequate option, especially in symptomatic cases. Compared with the current findings on CAS in nonagenarians (including our study), this would make it a more desirable option in cases of high grade stenoses and where medical management may be inadequate.

In summary, even with the observed bias of selection for patients who were in better condition at baseline, CAS in this high risk elderly group simply does not seem to carry the benefits it does in younger groups. The high risk of perioperative complications found in our study (as well as in larger work looking at CAS in the elderly ${ }^{7}$ ), doubts about the meaningful impact on longevity, and the existing option of CEA (and possibly medical management) having better results, all combine to make CAS appear less desirable both for symptomatic and asymptomatic nonagenarian patients.

Obvious limitations of this study are its retrospective nature and small sample size. Additionally, only CAS was used as a treatment option in our study, and research looking at CEA and medical management in a trial concurrently with CAS for a nonagenarian population would be most ideal. Further research in a prospective study would be desired and could be of benefit in helping us to learn ideal treatment methods for such a unique population of patients.

\section{CONCLUSION}

Although this case series is limited by its sample size owing to the small number of nonagenarian patients who were treated, it represents the largest analysis of data to date (to our knowledge) in this population. In symptomatic presentations of carotid stenosis, our results suggest a higher risk of perioperative complications than in the general population. CAS appears to provide little benefit to these patients and may potentially incur more risk than reward. In this series, asymptomatic nonagenarian patients also have a higher perioperative complication rate than the general population, and stenting also remains of questionable long term benefit in these patients. This series may suggest that CAS using current methodologies in patients older than 90 years of age is of questionable value as opposed to CEA (and possibly medical management), although more research is desired on this topic.

Acknowledgements The authors thank Paul H Dressel BFA for assistance with preparation of the illustrations and Debra J Zimmer for editorial assistance.

Contributors Conception and design: TMD. Drafting the manuscript: MMW and TMD. Acquisition of the data, analysis and interpretation of the data, critically revising the manuscript, and final approval of the manuscript: all authors.

Competing interests $\mathrm{LNH}$ receives grant/research support from Toshiba; serves as a consultant to Abbott, Boston Scientific, Cordis, Micrus, and Silk Road; holds financial interests in AccessClosure, Augmenix, Boston Scientific, Claret Medical, Endomation, Micrus, and Valor Medical; holds a board/trustee/officer position with Access Closure and Claret Medical; serves on Abbott Vascular's speakers' bureau; and has received honoraria from Bard, Boston Scientific, Cleveland Clinic, Complete Conference Management, Cordis, Memorial Health Care System, and the Society for Cardiovascular Angiography and Interventions (SCAI). EIL receives research grant support, other research support (devices), and honoraria from Boston Scientific, and research support from Codman and Shurtleff Inc and ev3/Covidien Vascular Therapies; has ownership interests in Intratech Medical Ltd and Mynx/Access 
Closure; serves as a consultant on the board of Scientific Advisors to Codman and Shurtleff Inc; serves as a consultant per project and/or per hour for Codman and Shurtleff Inc, ev3/Covidien Vascular Therapies, and TheraSyn Sensors, Inc; and receives fees for carotid stent training from Abbott Vascular and ev3/Covidien Vascular Therapies. ElL receives no consulting salary arrangements. All consulting is per project and/or per hour. AHS has received research grants from the National Institutes of Health (co-investigator: NINDS 1R01NS064592-01A1, Hemodynamic induction of pathologic remodeling leading to intracranial aneurysms) and the University at Buffalo (Research Development Award) (neither grant is directly related to the present work); holds financial interests in Hotspur, Intratech Medical, StimSox, Valor Medical, and Blockade Medical; serves as a consultant to Codman and Shurtleff Inc, Concentric Medical, Covidien Vascular Therapies, GuidePoint Global Consulting, Penumbra Inc, Stryker Neurovascular, and Pulsar Vascular; belongs to the speakers' bureaus of Codman and Shurtleff Inc and Genentech; serves on National Steering Committees for Penumbra Inc 3D Separator and Covidien SWIFT PRIME trials; serves on an advisory board for Codman and Shurtleff and Covidien Vascular Therapies; and has received honoraria from American Association of Neurological Surgeons' courses, Annual Peripheral Angioplasty, and All That Jazz Course, Penumbra Inc, and from Abbott Vascular and Codman and Shurtleff Inc, for training other neurointerventionists in carotid stenting and for training physicians in endovascular stenting for aneurysms. AHS receives no consulting salary arrangements. All consulting is per project and/or per hour. KVS serves as a consultant and a member of the speakers' bureau for Toshiba and has received honoraria from Toshiba. He serves as a member of the speakers' bureau for and has received honoraria from ev3 and the Stroke Group.

Ethics approval The University at Buffalo Health Sciences institutional review board approved the collection of data for the completion of this retrospective study.

Provenance and peer review Not commissioned; externally peer reviewed.

Data sharing statement Unpublished anonymized data may be available on a per request basis.

\section{REFERENCES}

1 Chastain HD II, Gomez CR, lyer S, et al. Influence of age upon complications of carotid artery stenting. UAB Neurovascular Angioplasty Team. J Endovasc Surg 1999;6:217-22.

2 Stanziale SF, Marone LK, Boules TN, et al. Carotid artery stenting in octogenarians is associated with increased adverse outcomes. J Vasc Surg 2006;43:297-304.

3 Wimmer NJ, Yeh RW, Cutlip DE, et al. Risk prediction for adverse events after carotid artery stenting in higher surgical risk patients. Stroke 2012;43:3218-24.

4 Zahn R, Ischinger T, Hochadel M, et al. Carotid artery stenting in octogenarians: results from the ALKK Carotid Artery Stent (CAS) Registry. Eur Heart J 2007;28:370-5.

5 Kinsella K, He W. An aging world: 2008. U.S. census bureau, international population reports P95/09-1. Washington, DC: US Government Printing Office, 2009. https://www. census.gov/prod/2009pubs/p95-09-1.pdf (accessed 15 Nov 2013).

6 Chaturvedi S, Matsumura JS, Gray W, et al. Carotid artery stenting in octogenarians: periprocedural stroke risk predictor analysis from the multicenter Carotid ACCULINK/ ACCUNET Post Approval Trial to Uncover Rare Events (CAPTURE 2) clinical trial. Stroke 2010;41:757-64.

7 Brott TG, Hobson RW II, Howard G, et al. Stenting versus endarterectomy for treatment of carotid-artery stenosis. N Engl J Med 2010;363:11-23.

8 Chiam PT, Roubin GS, Panagopoulos G, et al. One-year clinical outcomes, midterm survival, and predictors of mortality after carotid stenting in elderly patients. Circulation 2009;119:2343-8.

9 Gurm HS, Yadav IS, Fayad P, et al. Long-term results of carotid stenting versus endarterectomy in high-risk patients. N Engl J Med 2008;358:1572-9.

10 Meyer SA, Gandhi CD, Johnson DM, et al. Outcomes of carotid artery stenting in high-risk patients with carotid artery stenosis: a single neurovascular center retrospective review of 101 consecutive patients. Neurosurgery 2010;66:448-54.

11 Shetty RK, Vivek G, Gupta MK, et al. Carotid stenting in a nonagenarian patient with symptomatic carotid stenosis. Australas Med J 2012;5:528-30.

12 Faggioli GL, Ferri M, Freyrie A, et al. Aortic arch anomalies are associated with increased risk of neurological events in carotid stent procedures. Eur J Vasc Endovasc Surg 2007;33:436-41.

13 Lam RC, Lin SC, DeRubertis B, et al. The impact of increasing age on anatomic factors affecting carotid angioplasty and stenting. J Vasc Surg 2007:45:875-80.

14 Werner M, Bausback Y, Braunlich S, et al. Anatomic variables contributing to a higher periprocedural incidence of stroke and TIA in carotid artery stenting: single center experience of 833 consecutive cases. Catheter Cardiovasc Interv 2012:80:321-8.

15 Barbiero G, Cognolato D, Casarin A, et al. Carotid artery stenting in difficult aortic arch anatomy with or without a new dedicated guiding catheter: preliminary experience. Eur Radiol 2013;23:1420-8.

16 Dumont TM, Mokin M, Wach MM, et al. Understanding risk factors for perioperative ischemic events with carotid stenting: is patient age over 80 years or is unfavorable arch anatomy to blame? J Neurointerv Surg 2014:6:219-24.

17 Executive Committee for the Asymptomatic Carotid Atherosclerosis Study. Endarterectomy for asymptomatic carotid artery stenosis. JAMA 1995; 273:1421-8.

18 Ferguson GG, Eliasziw M, Barr HW, et al. The North American Symptomatic Carotid Endarterectomy Trial: surgical results in 1415 patients. Stroke 1999;30: 1751-8.

19 De Rango P, Lenti M, Simonte G, et al. No benefit from carotid intervention in fatal stroke prevention for $>80$-year-old patients. Eur I Vasc Endovasc Surg 2012:44:252-9.

20 Mateen FJ, Nasser M, Spencer BR, et al. Outcomes of intravenous tissue plasminogen activator for acute ischemic stroke in patients aged 90 years or older Mayo Clin Proc 2009;84:334-8.

21 North American Symptomatic Carotid Endarterectomy Trial Collaborators. Beneficial effect of carotid endarterectomy in symptomatic patients with high-grade carotid stenosis. N Engl J Med 1991;325:445-53.

22 Rothwell PM, Slattery J, Warlow CP. Clinical and angiographic predictors of stroke and death from carotid endarterectomy: systematic review. BMJ 1997; 315:1571-7.

23 Thygesen $\mathrm{K}$, Alpert JS, White HD. Universal definition of myocardial infarction. J Am Coll Cardiol 2007:50:2173-95.

24 Boysen G, Marott JL, Gronbaek M, et al. Long-term survival after stroke: 30 years of follow-up in a cohort, the Copenhagen City Heart Study. Neuroepidemiology 2009;33:254-60.

25 United States Social Security Administration. Actuarial life table. Period life table 2009. http://www.ssa.gov/OACT/STATS/table4c6.html (accessed 15 Nov 2013).

26 Dumont TM, Wach MM, Mokin M, et al. Perioperative complications after carotid artery stenting: a contemporary experience from the University at Buffalo neuroendovascular surgery team. Neurosurgery 2013; 73:689-94.

27 Ecker RD, Sauvageau E, Levy El, et al. Complications of carotid artery stenting at a high-volume teaching center: experience of University at Buffalo endovascular fellows from 2004 to 2006. Neurosurgery 2008;62:812-16.

28 Hobson RW II, Howard VJ, Roubin GS, et al. Carotid artery stenting is associated with increased complications in octogenarians: 30 -day stroke and death rates in the CREST lead-in phase. J Vasc Surg 2004;40:1106-11.

29 U.S. National Institutes of Health. ClinicalTrials.gov. Safety and efficacy study for Reverse Flow Used During Carotid Artery Stenting Procedure (ROADSTER). http://clinicaltrials.gov/ct2/show/NCT01685567 (accessed 15 Nov 2013).

30 Wallaert JB, Cronenwett JL, Bertges DJ, et al. Optimal selection of asymptomatic patients for carotid endarterectomy based on predicted 5-year survival. I Vasc Surg 2013;58:112-18.

31 Yadav JS, Wholey MH, Kuntz RE, et al. Protected carotid-artery stenting versus endarterectomy in high-risk patients. N Eng/ J Med 2004;351:1493-501.

32 Zafrir B, Laor A, Bitterman H. Nonagenarians in internal medicine: characteristics, outcomes and predictors for in-hospital and post-discharge mortality. Isr Med Assoc J 2010;12:10-15.

33 Chimowitz MI, Lynn MJ, Derdeyn CP, et al. Stenting versus aggressive medical therapy for intracranial arterial stenosis. N Engl J Med 2011; 365:993-1003.

34 Markus HS, Droste DW, Kaps M, et al. Dual antiplatelet therapy with clopidogrel and aspirin in symptomatic carotid stenosis evaluated using Doppler embolic signal detection: the Clopidogrel and Aspirin for Reduction of Emboli in Symptomatic Carotid Stenosis (CARESS) trial. Circulation 2005;111:2233-40.

35 Durward QJ, Ragnarsson TS, Reeder RF, et al. Carotid endarterectomy in nonagenarians. Arch Surg 2005;140:625-8.

36 Hingorani A, Ascher E, Schutzer R, et al. Carotid endarterectomy in octogenarians and nonagenarians: is it worth the effort? Acta Chir Belg 2004;104:384-7.

37 Killeen KL, Wagner WH, Cossman DV, et al. Carotid reconstruction in nonagenarians: is surgery a viable option? Ann Vasc Surg 2008;22: 190-4. 